\title{
Some ObServations on the Strength and Fatigue Properties of Samples EXTRACTED FROM CAST IRON WATER MAINS
}

\author{
H.M.S.Belmonte ${ }^{\mathrm{a}}$, M.J.Mulheron ${ }^{\mathrm{b}}$ and P.A.Smith ${ }^{\mathrm{b}}$ \\ a - Thames Water Utilities, Spencer House, Manor Farm Road, Reading, Berks RG2 0JN, UK \\ b - Faculty of Engineering and Physical Sciences, University of Surrey, Guildford, Surrey GU2 7XH, UK
}

\begin{abstract}
The strength and fatigue properties of cast iron samples taken from water distribution mains have been investigated. Specimens were sourced from three sections of pipe which had experienced varying amounts of corrosion in service, enabling the variable of pipe condition to be incorporated within the study.
\end{abstract}

The strengths in four-point flexure of small specimens from the pipes examined were described using Weibull statistics; different characteristic strengths and Weibull moduli were obtained, according to the pipe condition. A further set of samples from each pipe were subjected to flexural fatigue at a range of stress levels (different stress levels were chosen for each pipe based on the short-term strength properties) and residual strength tests were carried out on the surviving samples from one stress level for each pipe. There is evidence of a fatigue effect for all sample sets. There were slight differences in the residual strength behaviour - the residual strength of the survivors was reduced in the samples from the section in best condition while the residual strength of the survivors from the other two pipe sections was relatively unaffected. These trends are discussed with reference to condition and fatigue stress level.

The results suggest that mechanical fatigue may be a factor in the failure of water distribution pipes. The results may have implications for large diameter trunk mains as well as the small diameter water distribution pipes tested here. To assess the effect in more detail, consideration needs to be given to scaling effects in fatigue and the likely levels of any fatigue stress seen in service.

\section{Keywords}

Cast iron, Pipe, Fatigue, Weibull

\section{Introduction}

There is a body of literature concerned with various aspects of the condition assessment of cast iron water distribution pipes (e.g. refs 1 - 12). This reflects the challenge to the water industry of managing the operation of a supply and distribution network consisting of an ageing, predominantly cast iron infrastructure. In meeting this challenge, there has been a need to increase the body of scientific and engineering knowledge regarding the factors controlling the failure of these pipes in service, so as to support decisions made by the water companies. 
The size and scope of the problem is challenging. For example, a large part of the network operated by Thames Water Utilities comprises cast iron distribution pipes produced some 50 to 150 years ago and manufactured in various ways from different compositions. It is not surprising that they exhibit a range of mechanical behaviour. Added to this, the local corrosion environment around each pipe can vary significantly from street to street. Taken together, this gives rise to a population of pipes with significantly different characteristics, in terms of microstructure, manufacturing defects, corrosion behaviour and associated residual strength ${ }^{6,7} \& 10$. These pipe variables, taken in conjunction with the uncertainties regarding the pipe loading in service, make it difficult to identify those parts of the network that are in most urgent need of repair and replacement work.

The relationship between the failure load of a pipe and its in-service condition has attracted considerable interest in the water industry ${ }^{2,5} \& 8$. The reduction in strength as a result of corrosion can be analysed $d^{1,4}$ \& 9 on the basis of a loss of section (residual wall), or by using fracture mechanics. However, the inherent variability of the corrosion process and the need to characterise the pipe residual strength lends itself to the use of statistical models. For instance Sheikh $e t$ al. ${ }^{3}$ attempted a statistical approach to the modelling of pitting corrosion and pipeline reliability. Pitting was treated as a time-dependent stochastic damage process, whereby the time to perforation of the pipe was characterised using a Weibull extreme value reliability model. An inherent advantage of this approach is that it can deal with the wide variation in behaviour of apparently identical pipes without recourse to complicated procedures of analysis.

A Weibull approach has been used in other studies to understand the evolving defect populations that can arise as a cast iron pipe undergoes corrosion in service ${ }^{9,11 \& 12}$. This approach argues the initial strength of as-manufactured cast iron pipes is controlled by either casting defects (e.g. porosity and inclusions) or by microstructural defects (such as graphite flake/rosette geometry and size) inherent in the cast iron. Subsequent degradation in service leads to the strength of the pipe becoming governed by the defects introduced as a result of corrosion. It is suggested further (with reference to experimental data), that in such situations the strength data for cast iron pipes show both a reduced mean strength and a greater spread, as indicated by a lower Weibull modulus.

Once the strength of the material in a pipe has been degraded as a result of corrosion, there is obviously increased chance of failure of the pipe itself as a result of a loading experienced in service. Loading may have its origins from various sources, including internal pipe pressure, ground movement, traffic loading and temperature variation. Mechanical fatigue may also play a role. Cyclic loading could lead to subcritical crack growth from corrosion induced defects and hence eventually promote failure. This possibility does not appear to have been investigated systematically in the context of cast iron water pipes, although there are a number of studies concerned with fatigue crack growth in cast iron materials (e.g. refs. $13-16)$. 
The aim of the present study therefore is to examine the fatigue behaviour of samples of cast iron extracted from water distribution pipes, in particular with a view to understanding the stress levels needed to promote fatigue failure as a function of pipe condition.

The structure of the paper is as follows. In the next section, the cast iron pipe materials, specimens and scope of the experimental work are described. The results from the quasi-static strength tests are then presented, followed by the fatigue data, for which $S-N$ data and residual strength following load cycling were both investigated. The implications of the results for asset management in the water industry are then considered.

\section{Experimental}

\subsection{Material}

Three half metre sections of small diameter cast iron distribution pipe sections were sourced (courtesy of Thames Water Utilities) from one district metered area (DMA) in North London - these sections had been removed from full length pipes in service. The reference numbers (and corresponding diameters) for the sections were as follows: B22.03 (125 mm diameter), B22.14 (124 mm diameter), and H30.28 (122 mm diameter). Metallographic examination was carried out to verify that the pipes were a cast iron material, as opposed to ductile iron. To do this, small samples, approximately $20 \mathrm{~mm}$ x $20 \mathrm{~mm} \times$ the pipe wall thickness $(\sim 12.4 \mathrm{~mm})$, were cut from each pipe section and mounted in conducting Bakelite before polishing to a $0.25 \mu \mathrm{m}$ surface finish. The microstructures were examined using a Zeiss Axiophot light microscope with all the specimens being examined in the 'as-polished' state and then again after etching with $2 \%$ Nital (nitric acid in methanol) solution.

\subsection{Specimen Preparation for Mechanical Testing}

Test samples were cut along the length of the pipe section. These were $120 \mathrm{~mm}$ long and $10 \mathrm{~mm}$ wide, the final dimension being the pipe wall thickness. Preparing the specimens in this way meant that the top and bottom faces were not flat, but showed a (slight) curvature corresponding to the inner and outer diameter of the pipe. It was considered important to retain the whole thickness of the pipe, however, so that the effects of any defects (due to corrosion pits and graphitisation) on the outer and inner surfaces of the pipe were included in the test. After machining, the dimensions of each specimen were measured at three locations along the length and the average value determined. The same specimen geometry was used for the quasistatic and fatigue investigations. 


\subsection{Quasi-Static Flexure Testing}

\section{Test Method}

Specimens were tested to failure in bending using a four point bending rig mounted on an Instron $6025 \mathrm{R}$ quasi-static tensile test machine. The distance between the outer rollers on the bending rig was $100 \mathrm{~mm}$ and the distance between the inner rollers was $50 \mathrm{~mm}$. The rollers on the bending rig were $10 \mathrm{~mm}$ in diameter. The presence of the small radius of curvature of the specimens was accommodated in the flexure testing by placing strips of rubber between the specimen and the rollers of the bending rig. Specimens were loaded at a constant crosshead rate of $0.5 \mathrm{~mm} / \mathrm{min}$. and the subsequent load - time response recorded. The specimens were orientated so that the surface of the specimen associated with the outer surface of the original pipe section would experience the tensile stress. Previous in-house testing had shown that the cast irons under test behaved in a reasonably linear manner, especially at the (low) stress levels at which graphitised samples fail $^{11}$, and hence the approximation was made that elastic bending theory could be used to determine the fracture stress according to

$$
\sigma=\frac{M y}{I}
$$

where $\sigma$ is the stress at a distance $y$ from the neutral axis ( $y$ is set to half the specimen thickness), $M$ is the bending moment and $I$ is the second moment of area of the test specimen.

Fifteen specimens from each pipe were tested to failure in this way. Once the fifteen specimens for each pipe had been loaded to failure in four-point bending, the bend strengths were calculated and analysed using Weibull methods, as summarised below (more details of the method are given elsewhere ${ }^{11}$ ). This enabled appropriate load levels for fatigue testing to be identified.

\section{Data Analysis using Weibull}

According to the Weibull approach, the survival probability of a volume of material, subjected to a stress is given by:

$$
P_{s}(V)=\exp \left[-V\left(\frac{\sigma}{\sigma_{0}}\right)^{m}\right]
$$

The quantity $\sigma_{0}$ is the characteristic strength, which is a material constant (and is defined as the strength when the probability of survival is $\mathrm{e}^{-1}$, or about $37 \%$ ), and $m$, is the Weibull modulus, which is also a material constant and is a measure of the spread of the strength distribution.

The Weibull parameters ( $m$ and $\sigma_{0}$ ) are determined experimentally from tests on a number of samples $(N)$. The resulting failure strengths are ranked in ascending order and a survival probability is assigned to each 
sample. The survival probability for the $j^{\text {th }}$ sample in the rank is usually determined, for a small sample set, from:

$$
P_{s}=1-\frac{j-0.375}{N+0.25}
$$

Equations 2 and 3 can be found in most text books (e.g. Davidge ${ }^{17}$ and Watchman ${ }^{18}$ ).

Plotting a graph of $\ln \ln \left(1 / P_{s}\right)$ against $\ln (\sigma)$ enables the Weibull parameters to be determined. The slope of the linear line of best fit, for the data, is the value of the Weibull modulus while the value of the characteristic strength can be determined from the intercept of the $x$-axis.

\subsection{Fatigue Testing}

Specimens were subjected to fatigue loading using an Instron 1341 servo-hydraulic fatigue machine fitted with the four point bending rig. Tests were carried out in load control using a sinusoidal wave-form at a frequency of $5 \mathrm{~Hz}$. The fatigue stress ratio (minimum load divided by maximum load) was 0.1. Load and extension with cycles data were monitored using a PC-based data-logging package.

As the sample sets from each pipe had different characteristic strengths and Weibull moduli, the maximum load used in the fatigue tests was set at a level, determined from the Weibull analysis of the quasi-static data, to give a $90 \%$ probability of survival for that pipe on the first load cycle [see section 3.2]. Given the variation in condition, the intention of the tests was to subject a batch of 15 samples (the same number as tested quasi-statically) to a regime of fatigue loading $(1,000,000$ cycles at the load corresponding to a survival probability of $90 \%$ under short term loading) and then to examine the effect on the residual strength distribution as indicated by the Weibull plot for the survivors. This approach was successful for the sample sets from the two weakest pipe sections (B22.03 and B22.14). For the strongest pipe section (H30.38) it was necessary to reduce the fatigue load level considerably in order to get a reasonable number of samples to withstand the fatigue regime without failure [see section 3.2].

\subsection{Scanning Electron Microscopy}

The fracture surfaces of some of the specimens were examined using a variable pressure Hitachi Environmental S300N scanning electron microscope to compare the morphology of specimens failed quasistatically with those that experienced fatigue failure. 


\section{Results and Discussion}

\subsection{Quasi-static test results}

Metallographic investigation confirmed that the three pipe sections provided were cast iron and of a similar microstructure (the three pipes were sourced from the same DMA and if installed at approximately the same time, the similarity is not unexpected). The flake morphology was characterised as medium, consistent with the terminology [and specifically figure 3(d)] in ref. 11 .

As indicated in the previous section, 15 samples from each of the three pipes were tested to failure under quasi-static flexural loading and the nominal surface tensile stress at fracture was determined. The three sets of data were then analysed using Weibull statistics. This process is described in more detail

elsewhere ${ }^{11,12}$, but essentially the samples are assigned a survival probability based on their rank position amongst the fifteen tested and the data are then plotted as (standard) Weibull plots of $\ln \ln \left(1 / P_{s}\right)$ against $\ln (\sigma)$. The graphs are shown in figures 1 to 3 and the derived Weibull parameters are summarised in Table 1 .

The contrasting Weibull plots and Weibull parameters for the three pipes indicate that they have experienced different extents of corrosion in service. Pipe B22.03 is in poor condition with a low Weibull modulus and characteristic strength. Pipe H30.28 is in much better condition with a higher Weibull modulus and characteristic strength. The Weibull data for Pipe B22.14 (figure 2) display a degree of bimodality, which suggests that some of the pipe is in good condition, while other parts are in relatively poor condition. These effects have been described previously (reference 11).

The fracture surfaces shown in figure 4 provide support to these comments regarding pipe condition. This figure shows the fracture faces of the four point bending specimens from each pipe. The set of fifteen specimens from each pipe are arranged (from left to right) in order of increasing flexural strength. Both fracture surfaces of each specimen are shown; the top of the upper fracture face and the bottom of the lower fracture surface correspond to the surface of the specimen that experienced a tensile stress during testing and correspond to the outer surface of the pipe. The overall appearance of the fracture surfaces is similar, as would be expected given the microstructure of the three pipes. Rather different flaw populations can be seen in each set of samples. In figure 4(a), flaws associated with corrosion can be seen (originating at the outer surface of the pipe) and these flaws appear uniformly "large", whereas in figure 4(c) they are noticeably smaller. Figure 4(b) appears to contain a mixture, with some large flaws towards the left hand end of the row of samples and much smaller flaws towards the right hand end of the row. This is consistent with the results from the Weibull analysis, which suggested that the pipes were in three different conditions, with pipe H30.28 being in the best condition, pipe B22.03 being in the worst condition with pipe B22.14 being somewhere between the other two and further showing evidence of bimodality in the Weibull plot. [Note that a small number of samples display evidence of porosity in the fracture path - given that these 
pores are located away from the tensile surface of the flexure specimen, it is not thought that they played a significant role in the initiation of failure.]

\subsection{Fatigue}

\subsubsection{Fatigue Test Regime and Data Analysis}

A key aim of the fatigue study was to assess whether a period of fatigue loading could result in a measurable reduction in the residual quasi-static strength of samples from the pipe. To do this, a fatigue regime was chosen in which the peak load was set so as to produce a stress that would give the baseline pipe material a probability of survival of $90 \%$, according to the results of the initial quasi-static flexural testing. Residual strength tests were carried out on the batch of samples that survived $10^{6}$ cycles of fatigue loading. Given that a probabilistic method was used to identify a suitable fatigue load, this meant that different levels of loading resulted for the samples from each pipe section, ranging from $80 \mathrm{MPa}$ for the samples from Pipe B22.03, up to $160 \mathrm{MPa}$ for the samples from Pipe H30.28. In general, for a material with a low Weibull modulus the strength value predicted for a probability of survival of $90 \%$ is much lower that the average strength of that material (Pipe B22.03), while for a high Weibull modulus material the equivalent predicted strength will be only slightly smaller than the characteristic strength. It is important to note also that size effects mean that these levels of fatigue stress on small samples would be equivalent to much lower stresses on an entire pipe section, just as for quasi-static loading. Consequently, it is likely that these stresses are comparable with those that may be seen in service (a value of $90 \mathrm{MPa}$ is a figure that has been suggested previously as an upper estimate for the working stress in a distribution pipe ${ }^{8}$ ), although further consideration of Weibull scaling effects in fatigue would be required before any detailed quantitative predictions could be made.

It was decided that a minimum of ten specimens had to survive the fatigue regime in order to carry out a meaningful Weibull analysis of the residual quasi-static strength distribution. Hence specimens were fatigued until ten survivors were obtained. As a consequence the ten survivors of the fatigue loading did not necessarily make up the entire population of specimens subjected to fatigue, as there were specimens that did not survive a million cycles of fatigue loading. If those specimens that failed under fatigue loading were not considered in the Weibull analysis, the properties of the specimen population would be skewed as the weaker specimens will be removed. This would result in an artificially high Weibull modulus and characteristic strength. Hence, when determining the probability of survival for the residual strength samples (i.e. those that survived the fatigue loading) the probability was calculated on the whole population group and not just those specimens that survived the one million cycles of fatigue loading. Thus the analysis considers those specimens that failed during fatigue, although they cannot be shown on the Weibull plot, as they did not produce residual strength results. 
For pipes B22.03 and B22.14, this method worked well and there were an acceptable number of survivors at the chosen fatigue stress levels. For pipe H30.28, the fatigue peak stress was set initially at $~ 160 \mathrm{MPa}$, and at this stress level all samples failing before one million cycles. Hence for this pipe, samples were tested at a range of stress levels (leading to additional information regarding the S-N behaviour) until the applied fatigue peak stress was reduced to a level (135 MPa) at which a significant number of the specimens were able to survive one million cycles of fatigue loading.

\subsubsection{Fatigue Results}

\section{$S-N$ Data}

The data for specimens from each pipe that failed under fatigue loading are shown on a conventional S-N (stress against number of cycles to failure) plot in figure 5. For pipes B22.03 and B22.14, there is some variation around the nominal stress levels of $80 \mathrm{MPa}$ and $110 \mathrm{MPa}$, respectively, due to minor differences in specimen geometry from sample to sample (the peak fatigue load was kept constant, which leads to slight stress variations as the geometry changes).

It is apparent from the S-N data that mechanical fatigue failures were obtained for samples from each pipe. Given that pipe H30.28 was in "good" condition, the S-N curve for that material can be interpreted as typical for a grey cast iron under tension-tension fatigue loading. From the data for this pipe, it appears that a peak fatigue stress level of $50-60 \%$ of the short term strength leads to a fatigue life of around $10^{6}$ cycles, which seems reasonable. From the samples from pipes B22.03 and B22.14, it is clear that fatigue failures can occur at much lower stress levels in samples containing graphitised regions. The data for these two pipes show a large range of lives at the fatigue stress levels to which they were subjected with one sample from each pipe failing to survive the first cycle of loading. This behaviour is believed to be a consequence of the presence of different initial defect sizes - samples with larger defects will tend to fail in a smaller number of fatigue cycles. Whether the effect of graphitisation is to lead simply to a stress enhancement, due to a loss of effective section, or whether the graphitised regions act as pre-cracks, cannot be determined. However it is apparent that the fatigue performance of a corroded pipe is degraded significantly in respect of the same pipe at the point of installation. Given that the fracture toughness of cast iron is likely to be $10 \mathrm{MN} \mathrm{m}^{-3 / 2}$, then, based on fracture mechanics, the samples would be expected to tolerate the presence of cracks of several millimetres in depth. Hence it seems likely that there is appreciable sub-critical fatigue crack growth within the cast iron specimens before failure.

\section{Fracture Surfaces}

The fracture surfaces of specimens that had failed under fatigue and quasi-static loading were examined using a scanning electron microscope (SEM). Figures 6(a) and 6(b) show secondary electron images of 
representative features of these fracture surfaces. The fatigue failure surface, Figure 6(a), appears irregular and contains features that resemble fatigue striations of the sort that might be expected on examination of a fatigue surface. These features are not present on the fracture surface obtained under quasi-static loading, figure 6(b). While these observations are preliminary, they suggest there may be some occurrence of subcritical crack growth under fatigue loading.

\section{Residual Strength Data}

The residual strength data for the samples which survived the fatigue loading are shown on the same plots as the corresponding quasi-static data, i.e. figures 1-3. For each pipe, $15-20$ samples were tested in order to obtain the required number of survivors and hence the residual strength data correspond to the higher survival probability part of the Weibull plot. For the degraded pipe (B22.03) it appears that there has been no significant influence of fatigue loading on the strength distribution. This suggests that for these specimens there has been minimal crack growth in fatigue and that the defects already present in the corroded pipe dominate failure. For pipe B22.14 there is some indication of a bimodal distribution in the residual strength data, as well as in the original quasi-static strength data and again there is no discernible influence of fatigue loading on the strength distribution. This suggests that the defects in the weaker samples were sufficiently large that they propagated to failure during the $10^{6}$ cycles of fatigue loading but that the stress level was not high enough to cause defects to propagate further in the stronger samples. Thus for these samples, the corrosion defects already present continue to dominate failure even after the period of fatigue cycling. For the pipe in best condition (H30.28), however, there is a difference between the quasistatic and residual strength data and the Weibull modulus drops from a value of 7 (before fatigue loading) to 4 (after fatigue loading). This suggests that the development of fatigue damage and/or crack propagation is influencing the strength distribution, i.e. there has been a discernible weakening of the material.

These effects can be explored in more detail quantitatively as follows. For Pipe B22.03, the residual strength data (of the survivors) lie between around $160 \mathrm{MPa}$ and $230 \mathrm{MPa}$. As the fatigue loading level (80 $\mathrm{MPa}$ ) was a half of the lower of these residual strength values it is perhaps not surprising that the data suggests that there is no strength reduction as a result of the fatigue exposure. For Pipe B22.14, the residual strength data lie in the range $180 \mathrm{MPa}$ to $280 \mathrm{MPa}$ and that fatigue cycling to a stress of $110 \mathrm{MPa}$ has no observable effect. For pipe H30.28, the residual strength data lie in the range of $200 \mathrm{MPa}$ to $280 \mathrm{MPa}$ and the fatigue stress of $135 \mathrm{MPa}$ is almost $50 \%$ of this upper limit. Hence it is not surprising that, for this pipe, there is an effect of fatigue cycling on the residual strength.

\section{Concluding Remarks}


The aim of this study was to provide a preliminary assessment of the role of fatigue in the failure of water distribution pipes. The use of samples from three different pipes (of similar microstucture) enabled pipe condition to be considered in addition to stress level.

The different conditions of the pipes meant that their initial quasi-static strength distributions were different and this influenced the appropriate maximum fatigue stress to use for each pipe. It is important to emphasise that even the fatigue stress levels used for the samples from the pipe in best condition (130 - 160 MPa) may not be unrealistically high when viewed in the context of equivalent stresses in a full-size pipe section - the stresses in the full-size section will be significantly lower (and probably representative of those seen in service) due to scaling effects.

The study showed that samples from all three pipes experienced failure under fatigue loading. It was shown that the residual strength of the survivors was reduced in the samples from the section in best condition while the residual strength of the survivors from the other two pipe sections was relatively unaffected. This result can be understood in that the samples from the pipe in best condition were fatigued at stresses corresponding to a higher fraction of their initial quasi-static strength.

The observation that stable crack growth can occur under fatigue loading has potential implications for the survivability of cast iron water pipes in service. Thus some in service failures may be due to cyclic stresses that are relatively low, rather than due to a one-off transient. Clearly further work is necessary to unravel the implications of this observation for network asset management. This result may have particular implications in the context of large (cast iron) trunk mains.

\section{Acknowledgements}

The authors would like to acknowledge the support of Thames Water Utilities during the course of this work and, in particular, many helpful discussions with Professor Jeff Whiter. The opinions expressed in this paper are those of the authors and are not necessarily endorsed by the University of Surrey or Thames Water Utilities.

\section{References}

[1] Yamamoto, K., Mizoguti, S., Yoshimitsu, K. and Kawasaki, J. (1983). Relation Between Graphitic Corrosion and Strength of Cast Iron Pipes. Corrosion Engineering, 32(3), 157-162.

[2] Dempsey, P. and Manook, B.A. (1986). Assessing the Condition of Cast Iron Pipes. Source Document No.9 for the Water Mains Rehabilitation Manual, WRc Plc, Swindon. 
[3] Sheikh, A.K., Boah, J.K. and Hansen, D.A. (1990). Statistical Modelling of Pitting Corrosion and Pipeline Reliability. Corrosion, 46(3), 190-197.

[4] Conlin, R.M. and Baker, T.J. (1991). Application of Fracture Mechanics to the Failure Behaviour of Buried Cast Iron Mains. Transport Research Laboratory Contract Report No. 266.

[5] Randall-Smith et al. (1992). Guidance Manual for the Structural Condition Assessment of Trunk Mains. WRc plc.

[6] Makar, J. and Rajani, B. (2000). Grey Cast Iron Water Pipe Metallurgy. ASCE Journal of Construction Materials, 12, 245-253.

[7] Rajani, B. and Makar, J. (2000). A Methodology to Estimate Remaining Service Life of Grey Cast Iron Water Mains. Canadian Journal of Civil Engineering, 27, 1259-1272.

[8] Marshall, P. (2001). The Residual Structural Properties of Cast Iron Pipes - Structural and Design Criteria for Linings for Water Mains. Pipeline Innovation, UK Water Industry Research Limited, Report Ref. No. 01/WM/02/14.

[9] Atkinson, K., Whiter, J.T., Smith, P.A. and Mulheron, M. (2002). Failure of Small Diameter Cast Iron Pipes. Urban Water, 4(3), 263-271.

[10] Seica, M.V. and Packer, J.A. (2004). Mechanical Properties of Aged Cast Iron Water Mains. Journal of Materials in Civil Engineering, 16, 69-77.

[11] Belmonte, H.M.S., Mulheron, M.J. and Smith, P.A. (2007). Weibull Analysis, Extrapolations and Implications for Condition Assessment of Cast Iron Water Mains. Fatigue \& Fracture of Engineering Materials \& Structures, 30, 964-990.

[12] Belmonte, H.M.S., Mulheron, M.J., Smith, P.A., Ham A., Wescombe, K. and Whiter, J.T. (2008). Weibull Based Methodology for Condition Assessment of Cast Iron Water Mains and Its Application. Fatigue \& Fracture of Engineering Materials \& Structures, 31, 370-385.

[13] Kapadia, B.M and Imhof, E.J. (1979). Fatigue Crack Growth in Cast Iron and Cast Steel, in: Cast Metals for Structure and Pressure Containment Application. ASME-MPC-11. 
[14] Hornbogen, E. (1985). Fracture Toughness and Fatigue Crack Growth of Grey Cast Irons. Journal of Materials Science, 20, 3897 - 3905.

[15] James, M.N, and Li, W. (1999). Fatigue Crack Growth in Austempered Ductile and Grey Cast Irons Stress Ratio Effects in Air and Mine Water. Materials Science and Engineering, A265, 129 - 139.

[16] Baicchi, P., Collini, L. and Riva, E. (2007). A Methodology for the Fatigue Design of Notched Castings in Gray Cast Iron. Engineering Fracture Mechanics, 74, 539 - 548.

[17] Davidge RW (1979). Mechanical Behaviour of Ceramics. Cambridge University Press, Cambridge, UK.

[18] Wachtman JB (1996). Mechanical Behaviour of Ceramics. John Wiley \& Sons Inc, New York, USA. 


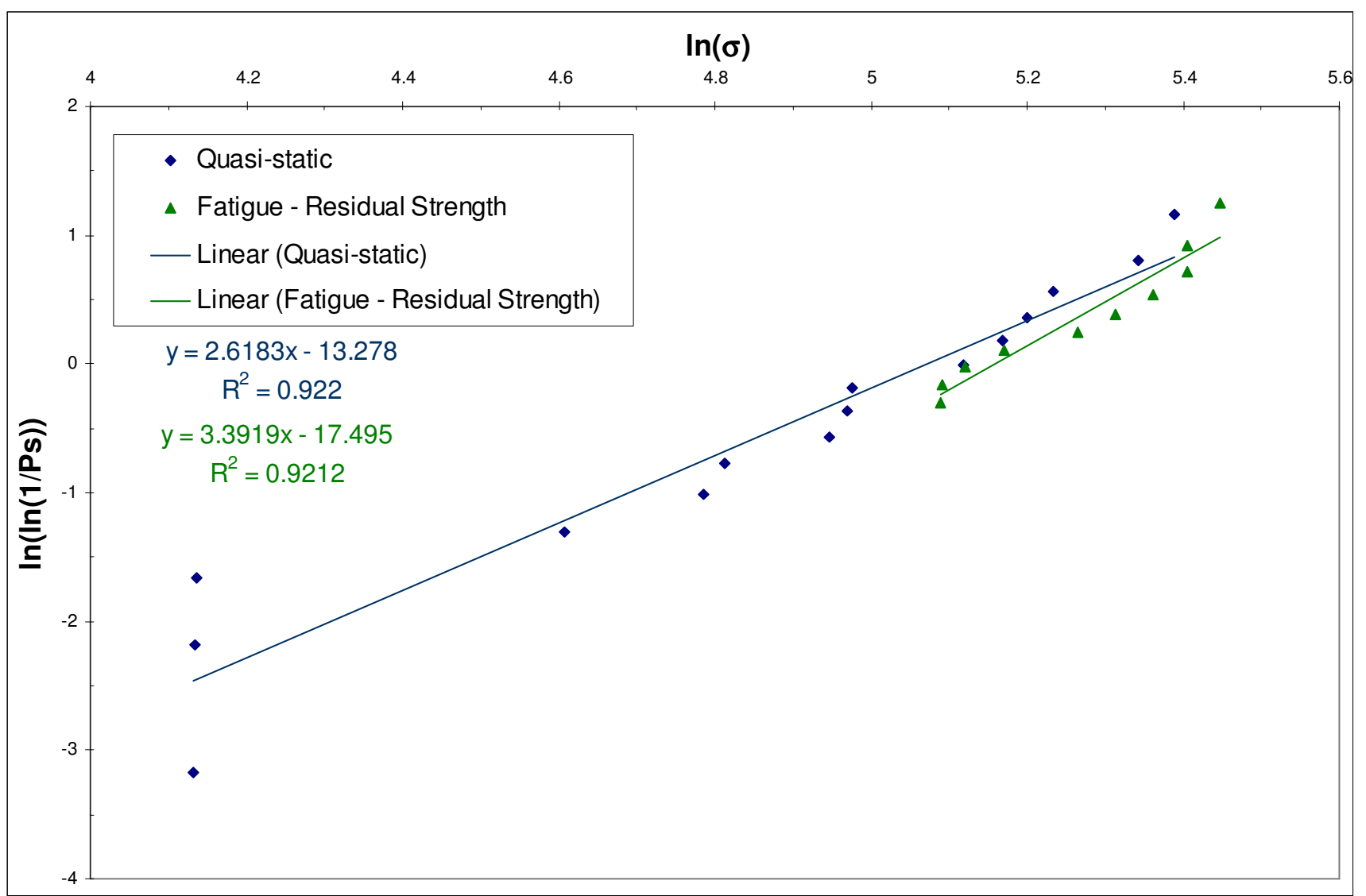

Fig. 1. Plot of $\ln \left(\ln \left(1 / P_{s}\right)\right)$ against $\ln (\sigma)$ for the set of quasi-static four-point bending tests (diamonds) and the residual strength after fatigue cycling (triangles) for Pipe B22.03 


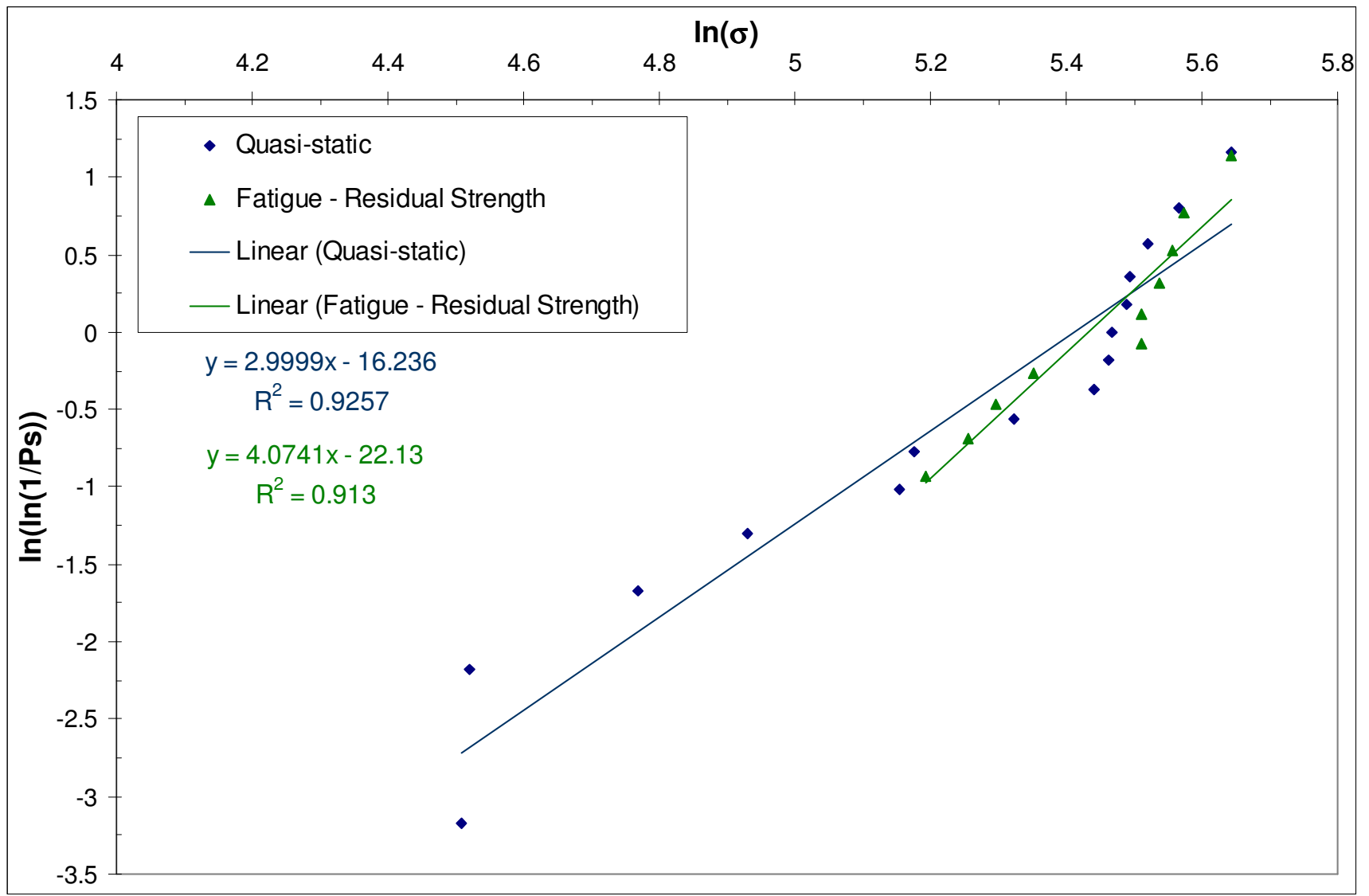

Fig. 2. Plot of $\ln \left(\ln \left(1 / P_{s}\right)\right)$ against $\ln (\sigma)$ for the set of quasi-static four-point bending tests (diamonds) and the residual strength after fatigue cycling (triangles) for Pipe B22.14 


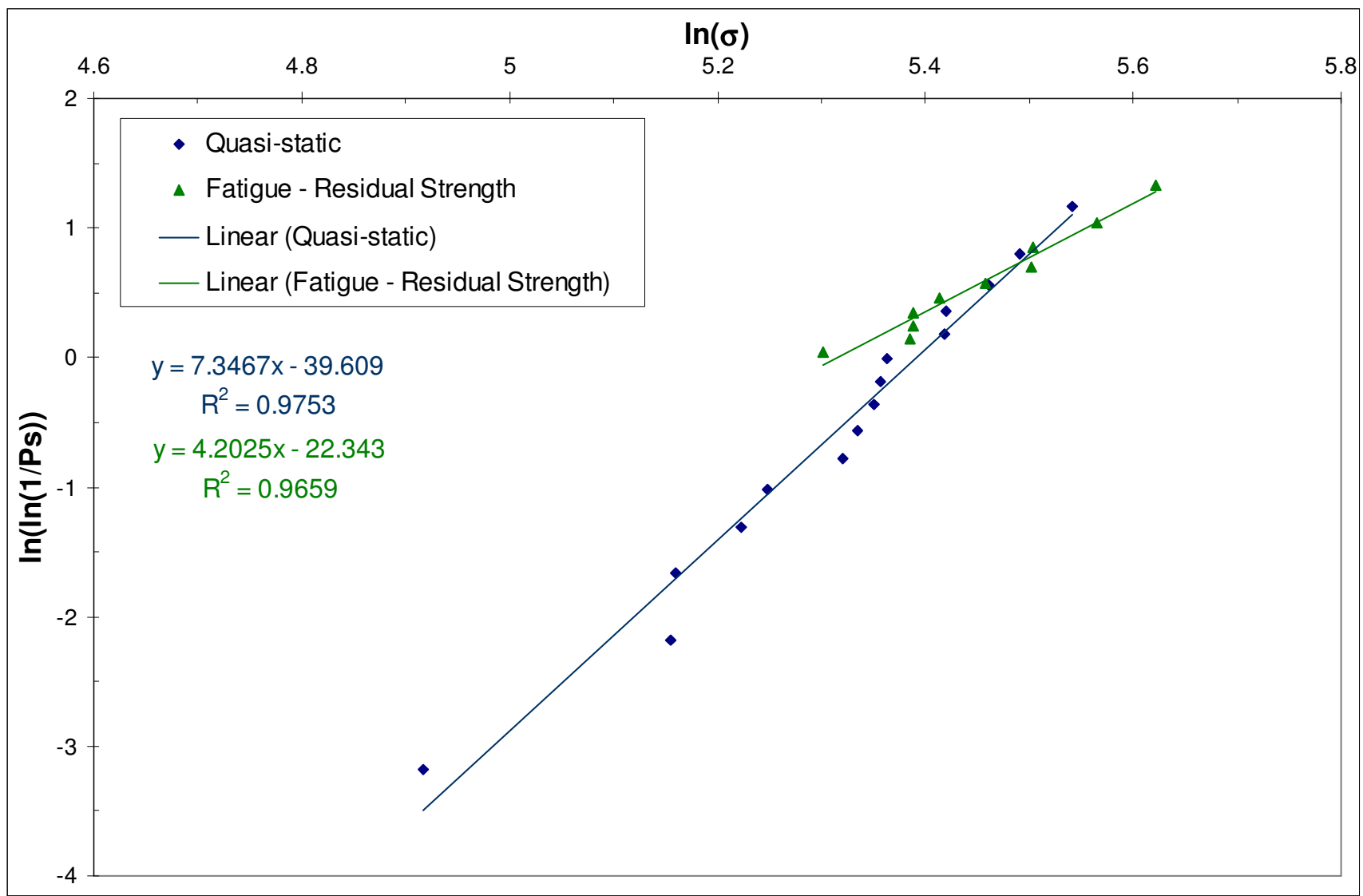

Fig. 3 Plot of $\ln \left(\ln \left(1 / P_{s}\right)\right)$ against $\ln (\sigma)$ for the set of quasi-static four-point bending tests (diamonds) and the residual strength after fatigue cycling (triangles) for Pipe H30.28 


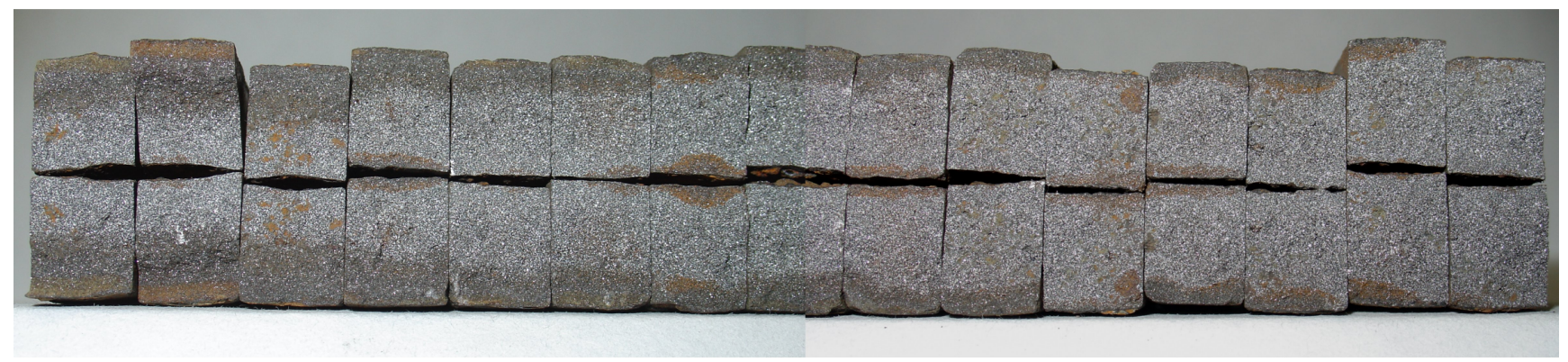

(a)

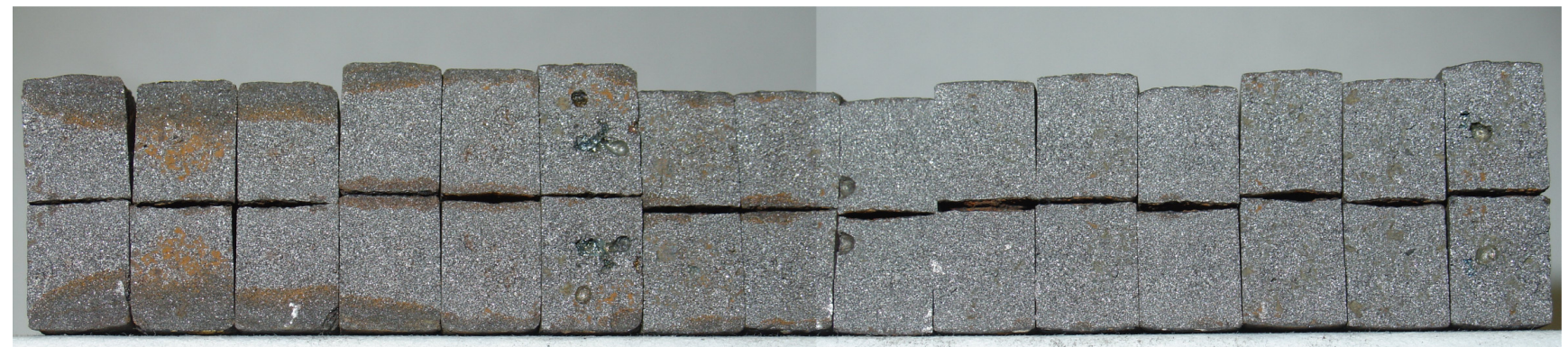

(b)

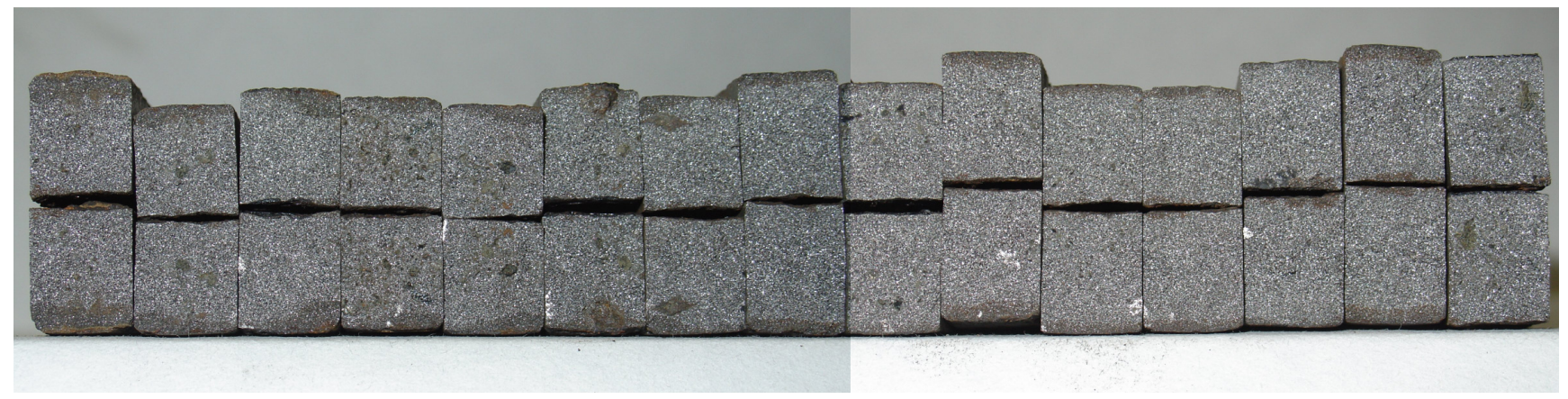

(c)

Fig. 4. Photographs of the fracture surfaces of the quasi-static four-point bend specimens for: (a) Pipe B22.03, (b) Pipe B22.14 and (c) Pipe H30.28 


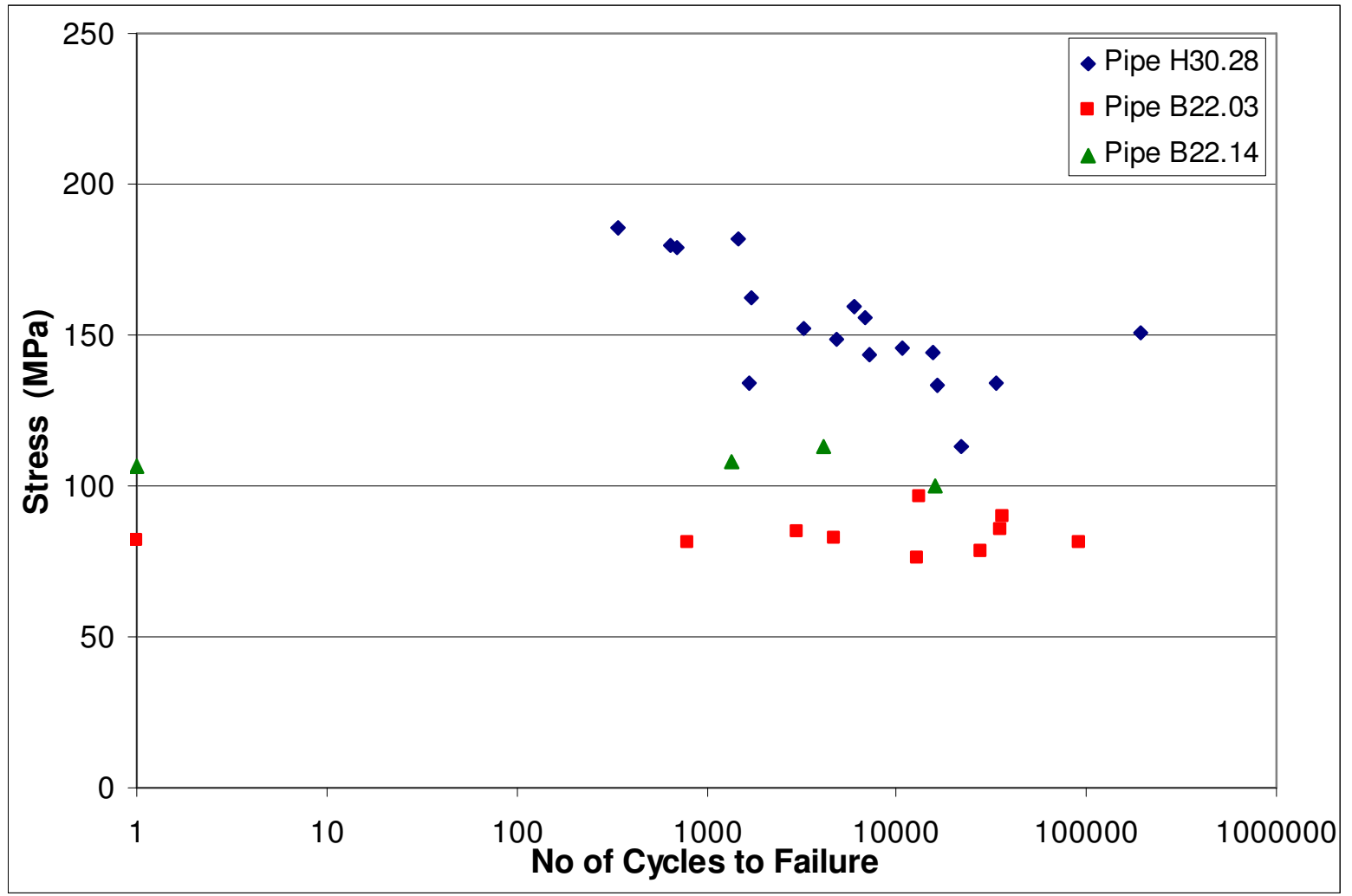

Fig. 5. Stress against number of cycles to failure for samples from each of the three pipes tested (the run out data for the survivors are not shown). 


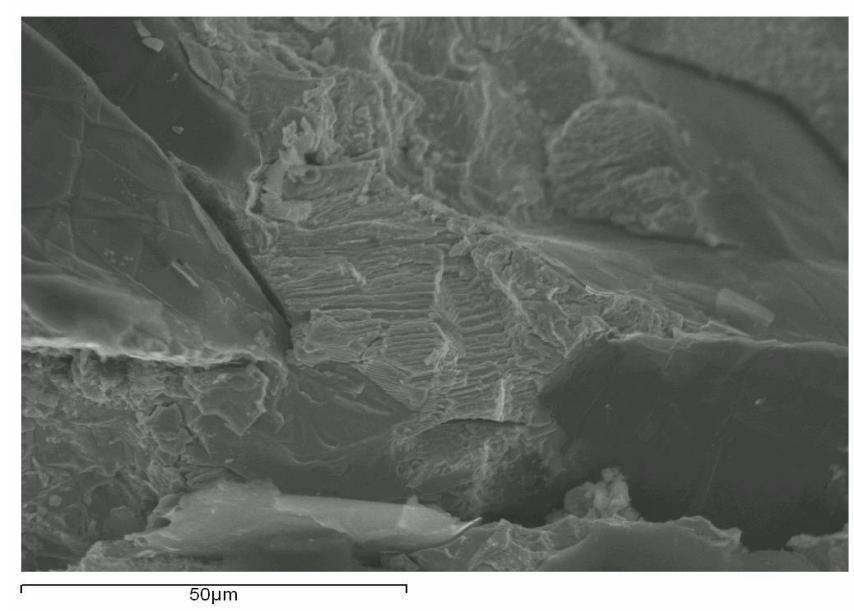

(a)

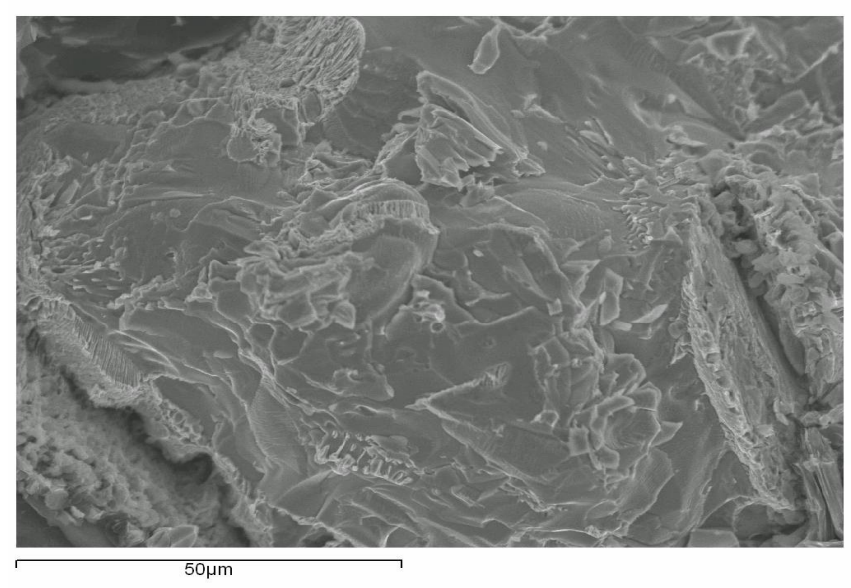

(b)

Fig. 6. Secondary electron micrographs showing the fracture surfaces of cast iron specimens failed: (a) under fatigue loading and (b) under quasi-static loading. 
Table 1 Summary of Weibull Parameters for samples from the three pipes. Note that the Quasi-Static column refers to data obtained from specimens loaded quasi-statically to failure in flexure, whilst the Residual Strength column refers to the small specimens first subjected to a fatigue loading for $10^{6}$ cycles (at a nominal stress level shown in the third column) after which they were tested to failure in flexure. The term $\sigma_{o}$ is the Weibull characteristic strength and $m$ is the Weibull modulus.

\begin{tabular}{|c|c|c|c|c|c|}
\hline \multirow{2}{*}{$\begin{array}{c}\text { Pipe } \\
\text { Reference }\end{array}$} & \multicolumn{2}{|c|}{ Quasi-Static } & \multicolumn{2}{|c|}{ Residual Strength } & \multirow{2}{*}{$\begin{array}{c}\text { Initial Peak Fatigue } \\
\text { Stress (MPa) } \\
\end{array}$} \\
\hline & $\sigma_{o}(\mathrm{MPa})$ & $m$ & $\sigma_{o}(\mathrm{MPa})$ & $m$ & \\
\hline B22.03 & 159 & 3 & 174 & 3 & 80 \\
\hline B22.14 & 224 & 3 & 229 & 4 & 110 \\
\hline H30.38 & 220 & 7 & 204 & 4 & 160 \\
\hline
\end{tabular}

